\title{
Effect of Intermittent Voltage Source Converter Faults on the Overall Performance of Wind Energy Conversion System
}

\author{
A. F. Abdou , Student Member IEEE, A. Abu-Siada, Senior Member IEEE and \\ H. R. Pota, Member IEEE
}

\begin{abstract}
The doubly fed induction generator (DFIG) is interfaced to the AC network through voltage source converters (VSCs) which are considered as the core of the DFIG system. This paper investigates the impact of different intermittent VSC faults on the overall performance of a DFIG-based wind energy conversion system (WECS). The fault ride through (FRT) capability of the DFIG under various VSC faults is also investigated. Faults such as open circuit and short circuit across the switches, when they occur within the grid side converter (GSC) and rotor side converter (RSC), are considered and compared in this paper. Short circuit and open circuit across the DC-link capacitor are also considered in this study as common VSC problems. Simulation results indicate that the short circuit faults have a severe impact on the overall performance of the DFIG, especially when they occur within the GSC. This is attributed to the fact that the GSC directly regulates the point of common coupling (PCC) voltage. The open circuit faults have less impact on the performance of the DFIG-based WECS. A proper controller along with FACT device should be available to compensate the required active and reactive power during these faults. A protection technique is necessary to detect these faults in advance to protect the VSC switches and the machine winding from any catastrophic failure.
\end{abstract}

Keywords:- WECS, DFIG, VSC faults, FRT, grid codes.

\section{List of Symbols and Acronyms}

$F \quad$ represent voltage or current

$P_{g} \quad$ grid side active power (W)

$v_{d c} \quad$ capacitor dc-voltage $(\mathrm{V})$

$i_{d c g} \quad$ grid side capacitor current (A)

$v_{d g} \quad$ grid side direct-axis voltage $(\mathrm{V})$

$i_{d g} \quad$ grid side direct-axis current (A)

$Q_{g} \quad$ grid side reactive power (VA)

$v_{q g} \quad$ grid quadrature-axis voltage (V)

$i_{q g} \quad$ grid quadrature -axis current (A)

$m$ pulse width modulation index

$i_{d c r} \quad$ rotor side capacitor current (A)

c capacitance (F)

$R_{g} \quad$ filter resistance $(\Omega)$

$L_{g} \quad$ filter inductance $(\mathrm{H})$

$\omega_{s} \quad$ synchronous angular speed (rad/s)

A. F. Abdou and H. R. Pota are with the School of ITEE, UNSW@ADFA, Canberra, Australia (e-mail: a.abdou@adfa.edu.au ), and (e-mail: h.pota@adfa.edu.au ).

A. Abu-Siada is with the Department of Electrical and Computer Engineering, Curtin University, Perth, WA 6845 Australia (e-mail: a.abusiada@curtin.edu.au). 


$\begin{array}{ll}v_{s d} & \text { stator direct-axis voltage }(\mathrm{V}) \\ v_{s q} & \text { stator quadrature-axis voltage (V) } \\ \omega_{r} & \text { the rotor speed (rad/s) } \\ \theta_{r} & \text { rotor angle (radian) } \\ P_{s} & \text { stator active power (W) } \\ Q_{s} & \text { stator reactive power (VA) } \\ i_{q r} & \text { rotor side quadrature-axis current (A) } \\ i_{d r} & \text { rotor side direct-axis current (A) } \\ i_{s d} & \text { stator direct-axis current (A) } \\ v_{s} & \text { stator voltage (V) } \\ L_{m} & \text { magnetizing inductance (H) } \\ L_{s} & \text { stator inductance (H) }\end{array}$

\section{INTRODUCTION}

WIND energy has become one of the most popular green renewable energy resources worldwide. During the period 1996 to 2011, the global annual installed wind energy capacity reached 238.351 GW [1]. The use of wind energy is still growing rapidly and it is expected to provide ten percent of the global electricity by 2020 [2]. Due to its known advantages over fixed-speed induction generators that include maximum power capture, less mechanical stresses, and less acoustical noise, $46.8 \%$ of the global installed wind turbines in 2002 were based on doubly fed induction generator (DFIG) which still dominate the wind energy conversion system (WECS) market [3],[4]. Compared with the full-converter variable-speed generators, the DFIG is a preferable choice in terms of size, cost, reduced losses and weight associated with the small converter [5]. The voltage source converters (VSCs) that interface the DFIG and the AC grid is rated at $30 \%$ of the generator power capacity for a rotor speed range of $\pm 30 \%$ [6]. This makes the DFIG-based WECS very sensitive to grid disturbances, especially to voltage fluctuation which can cause over voltages and over currents in the rotor windings that can lead to catastrophic failure of the wind turbine and the converter switches if no adequate protection scheme is installed [7]. The common solution to protect the converter from the rotor over current is by connecting a crowbar circuit across the rotor terminals that is activated when rotor currents exceed the maximum safety margin to isolate the converters from the rotor. On the other side, the DC-link over voltage is controlled by a resistive chopper that can dismiss the excess energy [8].

Due to the significant increase in wind turbine generators (WTGs) and the global trend to establish reliable smart grids, reliability of wind turbines has become one of the important concerns of the transmission system operators. Improved reliability of WTGs can be achieved by adopting robust protection scheme and effective measures for possible fault identification and quantification to avoid any catastrophic failures to the WECS. Wind turbines breakdown is attributable to defective / loose components or to malfunction in the turbine control systems. Fig. 1 shows the frequency of various causes for wind turbine breakdown from which the component failures represent the most frequent failure cause (36\%) followed by a malfunction within 
the control system (23\%) [9]. Turbine failure due to external grid faults or environmental conditions represent $19 \%$ of the frequent breakdown causes [9].

DFIG is interfaced to the AC network through voltage source converters (VSCs) which are considered as the crux of the DFIG system. Statistical surveys indicate that about $38 \%$ of power converter failures are due to issues with converter switches while $53 \%$ of failures are attributed to faults within converter control circuits [10, 11]. A recent industry-based survey indicates that the gate control circuits are the most susceptible components in converter faults [12]. Voltage source converters are subject to some common faults such as short and open circuit across the switch terminals, and DC-link failures [13-16]. These faults can be caused by various malfunctions in the control and firing equipment $[14,17]$. Although most of the internal converter faults are self clearing when the cause of these faults is of a transient nature [16], they can still have a significant impact on the overall performance of the WECS [18]. For such faults, system monitoring and diagnosis are essential to detect incipient faults to avoid any damages to the wind turbine and converter switches. Fault diagnosis could be achieved by measuring some qualitative parameters within the system while it is functioning normally. When these parameters violate preset threshold levels, proper protection scheme such as blocking the converters or disconnecting wind turbines from the AC grid should be triggered.

Many studies have given attention to the dynamic performance of DFIG-based WECS during various grid disturbances such as load fluctuation, voltage sag and swell and short circuit faults on the grid side [19-25]. While there are some studies that have investigated the effect of internal converter faults on the performance of high voltage direct current (HVDC) systems [26-28], no attention has been given to investigate the impact of such faults on the performance of the DFIG-based WECS and its compliance to recently developed grid codes.

This paper investigates the impact of various intermittent voltage source converter faults such as open circuit and short circuit across converter switches on the overall performance of WECS. The behavior of the system under study when the fault takes place within rotor side converter (RSC), and grid side converter (GSC) is compared and discussed. The effects of the studied faults on nine important parameters of the DFIG-based WECS are also investigated; in this way, fault identification and quantification can be achieved. Open and short circuit faults across the DC-link capacitor is also simulated in this study as a contributor to the internal VSC faults. Compliance of the DFIG performance under such faults with the fault ride through (FRT) grid codes of US, Spain, and Germany [29, 30] are also investigated.

\section{SySTEM DESCRIPTION AND CONTROLLER}

A single machine infinite bus (SMIB) system, shown in Fig. 2, qualitatively exhibits important characteristics of the behaviour of a multi-machine system; it is useful to describe the general concepts of power system stability and is relatively simple to study [31, 32]. The SMIB system shown in Fig. 2 is simulated using the EMTDC/PSCAD software to perform the investigations 
proposed in this paper. The DFIG stator terminals are connected to the grid through a coupling transformer and a short transmission line while the rotor windings are fed through back-to-back IGBT-based voltage source converters with a common DC-link capacitor and chopper to limit the capacitor over voltage. The GSC and the RSC of the DFIG are controlled by a vectorbased control as detailed in [33, 34] and briefly elaborated below.

\section{A. GSC PWM Vector Control}

The main task for GSC is to control the power exchange between the AC grid and the DC-link to maintain the dc voltage across the capacitor within permissible levels. By neglecting the switching harmonics and the converter losses, the flow of the active and reactive power $P_{g}$ and $Q_{g}$ exchange between the GSC and the AC grid can be calculated by [34]

$$
\begin{gathered}
P_{g}=v_{d c} i_{d c g}=\frac{3}{2} v_{d g} i_{d g} \\
Q_{g}=-\frac{3}{2} v_{d g} i_{q g}
\end{gathered}
$$

In the steady state operation, the grid voltage is constant and hence $v_{d g}$ is also constant. As a result, the active and reactive power can be controlled via controlling $i_{d g}$ and $i_{q g}$ as in Fig. 3.

According to [34] the relation between the dc-voltage and the grid side voltage can be calculated by

$$
v_{d g}=\frac{m}{2 \sqrt{2}} v_{d c}
$$

The dc-voltage as a function of the capacitor current can be given by

$$
c \frac{d v_{d c}}{d t}=i_{d c g}-i_{d c r}
$$

From (1), (3) and (4) the dc-voltage dynamic is described in terms of $i_{d g}$, as follows:

$$
c \frac{d v_{d c}}{d t}=\frac{3}{4 \sqrt{2}} m i_{d g}-i_{d c r}
$$

The grid side voltage in the synchronous rotating frame, can be calculated by

$$
\begin{aligned}
& v_{d g}=R_{g} i_{d g}+L_{g} \frac{d i_{d g}}{d t}-\omega_{s} L_{g} i_{q g}+v_{s d} \\
& v_{q g}=R_{g} i_{q g}+L_{g} \frac{d i_{q g}}{d t}+\omega_{s} L_{g} i_{d g}+v_{s q}
\end{aligned}
$$

Clarke-Park transformation [3] is used to convert the stator terminal currents from the d-q reference frame to the $\alpha-\beta$ reference frame as shown in Fig. 3 and given below.

$$
\begin{gathered}
\boldsymbol{F}^{d q g}=\boldsymbol{F}^{\alpha \beta g} \cdot e^{-j \omega_{s} t}=\boldsymbol{F}^{\alpha \beta g} \cdot e^{-j \theta_{s}} \\
\boldsymbol{F}^{d q r}=\boldsymbol{F}^{\alpha \beta r} \cdot e^{-j\left(\omega_{s}-\omega_{r}\right) t}=\boldsymbol{F}^{\alpha \beta r} \cdot e^{-j\left(\theta_{s}-\theta_{r}\right)}
\end{gathered}
$$


Fig. 3 shows that a proper reference level for the d-axis stator current $i_{\mathrm{dg}}^{*}$ is created using the voltage error signal across the DC-link capacitor and is compared with $i_{d g}$ to create an error signal that is used as an input to a proportional-integral (PI) controller. The level of q-axis reference current $i_{\mathrm{qg}}^{*}$ is selected to control the reactive power transfer between the GSC and the grid. The grid side controller output is used as an input to the pulse width modulation (PWM) circuit to create appropriate firing pluses to the GSC switches.

\section{B. RSC PWM Vector Control}

The RSC controls the generated active power according to the wind speed and the wind turbine characteristics while the reactive power command is set according to the utility requirements.

By ignoring the DFIG stator transients, the active and reactive power at the stator terminals can be calculated as

$$
\begin{gathered}
P_{s}=\frac{3}{2} v_{s d} i_{s d}=-\frac{3}{2} v_{s} \frac{L_{m}}{L_{s}} i_{d r} \\
Q_{s}=\frac{3}{2} v_{s d}\left(i_{q r}+\frac{v_{s d}}{\omega_{s} L_{m}}\right)
\end{gathered}
$$

Equations (10) and (11) imply that $P_{s}$ and $Q_{s}$ can be controlled by $i_{d r}$ and $i_{q r}$ respectively.

As shown in Fig. 4, a reference signal $\omega_{p u}^{*}$ is selected based on the wind turbine characteristics to track the maximum power and it is compared with the measured rotor speed to create an error signal that is fed to a PI controller to generate the q-axis rotor current $i_{q r}^{*}$. To achieve unity power factor operation, the reactive power reference $Q_{S}^{*}$ is set to zero and is compared with the measured value to create an error signal that is fed to another PI controller to generate the reference rotor d-axis current $i_{d r}^{*}$. Clarke-Park transformation is used to convert $i_{q r}^{*}$ and $i_{d r}^{*}$ to $i_{a b c}^{*}$ which is used as input to the RSC PWM circuit along with $i_{\mathrm{abc}}$ to create appropriate firing pulses to the RSC switches.

\section{Simulation Results}

To study the impacts of the VSC faults on the overall performance of the DFIG-based WECS, the system shown in Fig. 2 along with the control circuits shown in Fig. 3 and 4, are simulated using EMTDC/PSCAD software. The DFIG is assumed to operate at unity power factor, as mentioned in Section II, and at an average wind speed of $11.5 \mathrm{~m} / \mathrm{s}$. The DFIG is initialized with a speed of 1.054 pu to pass the initial transient period, then switched to the torque control at $\mathrm{t}=0.5 \mathrm{~s}$.

The crowbar circuit is deactivated to study the impact of the VSC faults on the dynamic performance of the DFIG-based WECS. In all studied cases, faults are assumed to last for 0.5s and the dynamic performance of the DFIG-based WECS under various intermittent VSC faults are investigated through time domain waveforms of various system variables such as the voltage across the DC-link capacitor, DFIG active power, rotor shaft speed, electrical torque, DFIG reactive power, terminal voltage, and 
the rotor and stator currents. Furthermore, the voltage at the point of common coupling (PCC) is compared to the FRT of US, Spain, and Germany grid codes. Results are given in the same aforementioned order.

\section{A. Switches short circuit}

The converter switch short circuit can be caused due to a fire-through or flashover across the switch $[14,16]$. As defined in the literature, fire-through is the conduction of a switch before its programmed instant of conduction $[14,16]$. Fig. 5 shows the transient time responses of the DFIG during an intermittent fire-through across switch T3 in the RSC and GSC. Fig. 5 (a) indicates that this fault has a significant impact on the DC-link capacitor voltage as it drastically reduces throughout fault duration. The impact, however, is worse when the fault takes place within the GSC, which directly controls the DC-link capacitor voltage as previously explained in Section II.

The generated active power experiences transient oscillations during fault. When the fault is cleared at $t=6.5 \mathrm{~s}$, the power drops to a negative level and the machine tends to absorb about 1.5 pu active power from the grid for a few cycles after which it increases gradually. However it does not retain its steady state level especially in case of the fault occurrence within RSC where the machine continues to absorb active power from the grid and acts as an induction motor. The rotor shaft speed is reduced accordingly as shown in Fig. 5 (c) and is recovered to its nominal value at $t=8 \mathrm{~s}$ for both fault locations. The electrical torque shown in Fig. 5 (d) experiences overshooting at the instant of fault occurrence; the effect of RSC is more pronounced. When the fault occurs within the RSC, the DFIG draws about 1.35 pu reactive power from the grid for a few cycles before it retains steady state zero level after fault clearance as shown in Fig. 5 (e). In case of fire-through fault within the GSC, the DFIG draws about $1.8 \mathrm{pu}$ of reactive power upon the occurrence of the fault at $t=6 \mathrm{~s}$ and then it exhibits an overshooting of 2 pu upon fault clearance before it settles down to the steady state zero level at $t=7.3 \mathrm{~s}$. The voltage at the machine terminal experiences a voltage dip of $20 \%$ in case of fire-through within RSC and more than $45 \%$ in case of fire-through within the GSC; in both cases the steady state voltage level is not retained after fault clearance as shown in Fig. 5 (f). The rotor current increases to 1.5 pu in the case of RSC fire-through and to $0.75 \mathrm{pu}$ in the case of GSC fire-through which introduces a maximum overshooting of $1.5 \mathrm{pu}$ to the rotor current at the instant of fault clearance as shown in Fig. 5 (g). In both cases, rotor current does not violate the common tolerable limit of 2 pu as specified in [8]. Fig. 5 (h) shows that the stator current is significantly increased by 4 pu for the entire fault duration in case of RSC fire-through and is increased by 1.8 pu in case of GSC fire-through.

Compared with US, Spain, and Germany FRT grid codes, the voltage at the point of common coupling (PCC) violates the low voltage ride through (LVRT) level of Spain and Germany in case of fire-through within the GSC. However, in case of firethrough within the RSC, voltage at the PCC is within the safe margins of all grid codes under study (Fig. 5 (i)). 
These results show that, unless adequate control and protection system is adopted, the consequences will be far reached and the wind turbine must be disconnected to avoid any damages. Protection devices such as crowbar and dc-chopper should be activated during the fault to protect the converter against excessive current in this case.

\section{B. Switches open circuit}

Misfire is the failure of a switch to take over conduction at the programmed instant [14, 16, 17, 35]. This fault may take place within a converter switches due to many reasons such as driver open circuit, control circuit element deterioration, or degraded electromagnetic compatibility [17]. The impact of this type of fault on the overall system performance, when it takes place on switch T3 in the RSC and GSC at $\mathrm{t}=6 \mathrm{~s}$ and lasts for 0.5s, is shown in Fig. 6. Unlike the case of fire-through fault, the voltage across the DC-link capacitor is not affected by the misfire within the RSC, and it slightly oscillates at the instant of fault clearance when misfire occurs within the GSC as shown in Fig. 6 (a). The DFIG active power is subjected to slight oscillations during fault, which is more visible in case of misfire within the RSC as shown in Fig. 6 (b). Rotor shaft speed shown in Fig. 6 (c) is not impacted by this fault when it takes place within the GSC or RSC. Fig. 6 (d, e) show that the electrical torque experiences oscillatory pulses during a misfire within the RSC and the machine absorbs some reactive power from the grid to compensate for these oscillations. However, the effect of GSC misfire on these variables is insignificant. The same trend can be seen in the generator terminal voltage, rotor and stator currents shown in Fig. 6 (f, g and h) respectively.

The voltage at the PCC is within the safe margins of the FRT of all studied grid codes as shown in Fig. 6 (i). It is worth mentioning that in all studied cases, the effect of misfire when occurs within the RSC is more pronounced than the effect of the same fault when it takes place within the GSC. Simulation results conclude that intermittent misfire within GSC and RSC will not activate any protection devices such as the crowbar circuit as all system parameters are within safe permissible levels.

\section{DC Link Capacitor Failure}

In these types of faults, the DC-link capacitor is assumed to experience intermittent open and short circuit faults. Both faults are assumed to take place across the capacitor at $t=6 \mathrm{~s}$ for a duration of $0.5 \mathrm{~s}$. The effect of these faults on the overall performance of the system under study is shown in Fig. 7.

While open circuit fault has almost no impact on the DFIG dynamic performance, the impact of short circuit fault is noticeable. When short circuit takes place across the capacitor terminals, the DC-link voltage level as shown in Fig. 7 (a) drops to zero at the instant of fault application and it is recovered after fault clearance due to the control action of the GSC. The DFIG active power exhibits damped oscillations during the fault and its direction is reversed at the instant of fault clearance before it retains its nominal steady state level in $0.7 \mathrm{~s}$ as can be seen in Fig. 7 (b). The rotor shaft speed (Fig. 7 (c)) slightly retards through fault duration and settles after fault clearance. The electrical torque experiences damped oscillations throughout fault duration (Fig. 7 
(d)). Upon fault occurrence, the DFIG behaves as an induction motor as it tends to absorb significant reactive power from the grid (2.0 pu) as shown in Fig. 7 (e) which also shows a maximum overshooting of 4.0 pu is introduced to the generated reactive power at the instant of fault clearance before it settles down to zero level due to the action of RSC controller. As shown in Fig. 7 (f), short circuit fault introduces $25 \%$ voltage sag to the DFIG terminal voltage. When the fault is cleared, the terminal voltage exhibits a maximum overshooting of 1.4 pu before it settles down to its steady state level. Short circuit fault produces excess current within stator and rotor windings, which reaches crest values of $5.5 \mathrm{pu}$ and $1.8 \mathrm{pu}$, respectively, at the instant of fault clearance (Fig. 7 (g)).

Compared with the FRT grid codes of the US, Spain, and Germany the voltage at the PCC violates the high voltage ride through (HVRT) level of these grid codes when short circuit takes place across the DC-link capacitor which calls for the disconnection of the wind turbine, to avoid any possible damages, as HVRT does not comply with grid code requirements.

The above results show that faults such as fire-through and short circuit across the dc-link capacitor may lead to the disconnection of the wind turbine and damages to the converter switches unless a reliable protection scheme and robust controller are adopted. As these faults are of transient nature, a proper flexible AC transmission system (FACTS) device such as unified power flow controller (UPFC) [36], superconducting magnetic energy storage (SMES) unit [26] and static compensator (STATCOM) [18] with a proper control system that aids in increasing system damping by modulating active and/or reactive power during the aforementioned faults is suggested. The FACTS control system should be designed based on comparing the performance of the WECS through some key parameters investigated above such as voltage at the PCC and DFIG generated active power with the normal operating condition characteristics. Any significant deviation in any key parameter that violates the threshold level of this parameter should trigger the FACTS control system to provide a correction action.

\section{CONCLUSION}

In this paper, simulation studies are performed to investigate the impact of different intermittent VSC faults on the overall performance of DFIG-based WECS. Faults such as short circuit and open circuit across the converter switches, when they occur within GSC and RSC are considered and compared. Compliance of the WECS under such faults with the FRT of US, Spain, and Germany grid codes are also investigated. Simulation results show that open circuit faults within converter switches and open circuit fault across the DC-link capacitor have less impact on the DFIG dynamic performance while short circuit faults across the switches and across the DC-link capacitor will lead to excess currents in both rotor and stator winding and may lead to the disconnection of the wind turbine from the grid to avoid any catastrophic failure to the wind turbine or to the converter switches.

The effect of internal VSC faults should be considered in the DFIG control system design and reactive power compensation must 
be available to enable the wind turbine to comply with the stringent FRT specifications enforced by the international grid codes.

Moreover, a reliable condition monitoring technique is necessary to detect these faults in advance in order to prevent the severe

consequences of such faults.

\section{REFERENCES}

[1] "Global Wind Statistics 2011," http://www.gwec.net/ 07.02.2012.

[2] P. Musgrove, Wind Power. New York: Cambridge University Press, 2010.

[3] T. Ackermann, Wind Power in Power System. West Sussex: John Wiley and Sons Ltd, 2005.

[4] M. Mohseni, S. M. Islam, and M. A. S. Masoum, "Impacts of Symmetrical and Asymmetrical Voltage Sags on DFIG-Based Wind Turbines Considering Phase-Angle Jump, Voltage Recovery, and Sag Parameters," Power Electronics, IEEE Transactions on, vol. 26, pp. 1587-1598, 2011.

[5] A. Petersson and S. Lundberg, "Energy Efficiency Comparison of Electrical Systems for Wind Turbines," presented at the Nordic Workshop on Power and Industrial Electronics, Stockholm, Sweden 2002.

[6] C. Zhe, J. M. Guerrero, and F. Blaabjerg, "A Review of the State of the Art of Power Electronics for Wind Turbines," Power Electronics, IEEE Transactions on, vol. 24, pp. 1859-1875, 2009.

[7] J. Lopez, P. Sanchis, X. Roboam, and L. Marroyo, "Dynamic Behavior of the Doubly Fed Induction Generator During Three-Phase Voltage Dips," Energy Conversion, IEEE Transactions on, vol. 22, pp. 709-717, 2007.

[8] M. Rahimi and M. Parniani, "Transient Performance Improvement of Wind Turbines With Doubly Fed Induction Generators Using Nonlinear Control Strategy," Energy Conversion, IEEE Transactions on, vol. 25, pp. 514-525, 2010.

[9] M. D. S Faulstich, B Hahn, K Knorr, K Rohrig, "Windenergy Report Germany 2008," Institut für Solare Energieversorgungstechnik (ISET),2008.

[10] H. B. A. Sethom and M. A. Ghedamsi, "Intermittent Misfiring Default Detection and Localisation on a PWM Inverter Using Wavelet Decomposition," Journal of Electrical Systems, vol. 4, 2008.

[11] F. W. Fuchs, "Some diagnosis methods for voltage source inverters in variable speed drives with induction machines - a survey," in Industrial Electronics Society, 2003. IECON '03. The 29th Annual Conference of the IEEE, 2003, pp. 1378-1385 Vol.2.

[12] Y. Shaoyong, A. Bryant, P. Mawby, X. Dawei, R. Li, and P. Tavner, "An Industry-Based Survey of Reliability in Power Electronic Converters," Industry Applications, IEEE Transactions on, vol. 47, pp. 1441-1451, 2011.

[13] J. Arrillaga, Y. H. Liu, and N. R. Watson, Flexible power transmission: the HVDC options: John Wiley, 2007.

[14] J. Arrillaga, High voltage direct current transmission: Institution of Electrical Engineers, 1998.

[15] L. Bin and S. K. Sharma, "A Literature Review of IGBT Fault Diagnostic and Protection Methods for Power Inverters," Industry Applications, IEEE Transactions on, vol. 45, pp. 1770-1777, 2009.

[16] K. R. Padiyar, HVDC power transmission systems: technology and system interactions: Wiley, 1990.

[17] L. Bin and S. Sharma, "A survey of IGBT fault diagnostic methods for three-phase power inverters," in Condition Monitoring and Diagnosis, 2008. CMD 2008. International Conference on, 2008, pp. 756-763.

[18] A. F. Abdou, A. Abu-Siada, and H. R. Pota, "Application of STATCOM to improve the LVRT of DFIG during RSC fire-through fault," in Universities Power Engineering Conference (AUPEC), 2012 22nd Australasian, 2012, pp. 1-6.

[19] H. Sheng, L. Xinchun, K. Yong, and Z. Xudong, "An Improved Low-Voltage Ride-Through Control Strategy of Doubly Fed Induction Generator During Grid Faults," Power Electronics, IEEE Transactions on, vol. 26, pp. 3653-3665, 2011.

[20] A. O. Ibrahim, N. Thanh Hai, L. Dong-Choon, and K. Su-Chang, "A Fault Ride-Through Technique of DFIG Wind Turbine Systems Using Dynamic Voltage Restorers," Energy Conversion, IEEE Transactions on, vol. 26, pp. 871-882, 2011.

[21] A. M. Shiddiq-Yunus, A. Abu-Siada, and M. A. S. Masoum, "Application of SMES Unit to Improve The Voltage Profile of The System With DFIG During Grid Dip and Swell," International Journal of Advances in Engineering \& Technology, vol. 1, pp. 1-13, 2011.

[22] A. Rolan, F. Corcoles, and J. Pedra, "Doubly Fed Induction Generator Subject to Symmetrical Voltage Sags," Energy Conversion, IEEE Transactions on, vol. 26, pp. 1219-1229, 2011.

[23] D. Campos-Gaona, E. L. Moreno-Goytia, O. Anaya-Lara, and G. Burt, "Ride-through-fault capabilities of DFIG wind farm connected to a VSC station during a DC fault," in AC and DC Power Transmission, 2010. ACDC. 9th IET International Conference on, 2010, pp. 1-5.

[24] L. Xin, Z. Tao, C. Yongning, and W. Weisheng, "Short Circuit Current Characteristic of Wind Generators," in Power and Energy Engineering Conference, 2009. APPEEC 2009. Asia-Pacific, 2009, pp. 1-4.

[25] R.-M. He, J.-L. Wang, J. Ma, Y.-H. Xu, and D. Han, "Impacts of DFIG-based wind farm on load modeling," in Power \& Energy Society General Meeting, 2009. PES '09. IEEE, 2009, pp. 1-6.

[26] A. Abu-Siada and S. Islam, "Application of SMES Unit in Improving the Performance of an AC/DC Power System," Sustainable Energy, IEEE Transactions on, vol. 2, pp. 109-121.

[27] H. A. Darwish, A. M. I. Taalab, and M. A. Rahman, "Performance of HVDC converter protection during internal faults," in Power Engineering Society General Meeting, 2006. IEEE, 2006, p. 7.

[28] S. O. Faried and A. M. El-Serafi, "Effect of HVDC converter station faults on turbine-generator shaft torsional torques," Power Systems, IEEE Transactions on, vol. 12, pp. 875-881, 1997.

[29] M. Tsili and S. Papathanassiou, "A review of grid code technical requirements for wind farms," Renewable Power Generation, IET, vol. 3, pp. 308332, 2009.

[30] M. Altin, O. Goksu, R. Teodorescu, P. Rodriguez, B. B. Jensen, and L. Helle, "Overview of recent grid codes for wind power integration," in Optimization of Electrical and Electronic Equipment (OPTIM), 2010 12th International Conference on, 2010, pp. 1152-1160.

[31] G. Gurrala and I. Sen, "A Nonlinear Voltage Regulator With One Tunable Parameter for Multimachine Power Systems," Power Systems, IEEE Transactions on, vol. 26, pp. 1186-1195, 2011.

[32] A. F. Abdou, A. Abu-Siada, and H. R. Pota, "Application of a STATCOM for damping subsynchronous oscillations and transient stability improvement," in Universities Power Engineering Conference (AUPEC), 2011 21st Australasian, 2011, pp. 1-5.

[33] L. Shuhui and T. A. Haskew, "Analysis of Decoupled d-q Vector Control in DFIG Back-to-Back PWM Converter," in Power Engineering Society General Meeting, 2007. IEEE, 2007, pp. 1-7.

[34] R. Pena, J. C. Clare, and G. M. Asher, "Doubly fed induction generator using back-to-back PWM converters and its application to variable-speed wind-energy generation," Electric Power Applications, IEE Proceedings -, vol. 143, pp. 231-241, 1996.

[35] K. S. Smith, R. Li, and J. Penman, "Real-time detection of intermittent misfiring in a voltage-fed PWM inverter induction-motor drive," Industrial Electronics, IEEE Transactions on, vol. 44, pp. 468-476, 1997. 
[36] J. P. Therattil and P. C. Panda, "Non-linear Dynamic Modeling and Adaptive Control of a Power System with Unified Power Flow Controller," Electric Power Components and Systems, vol. Volume 40, pp. 1544-1561, 2012.

\section{List of figures:}

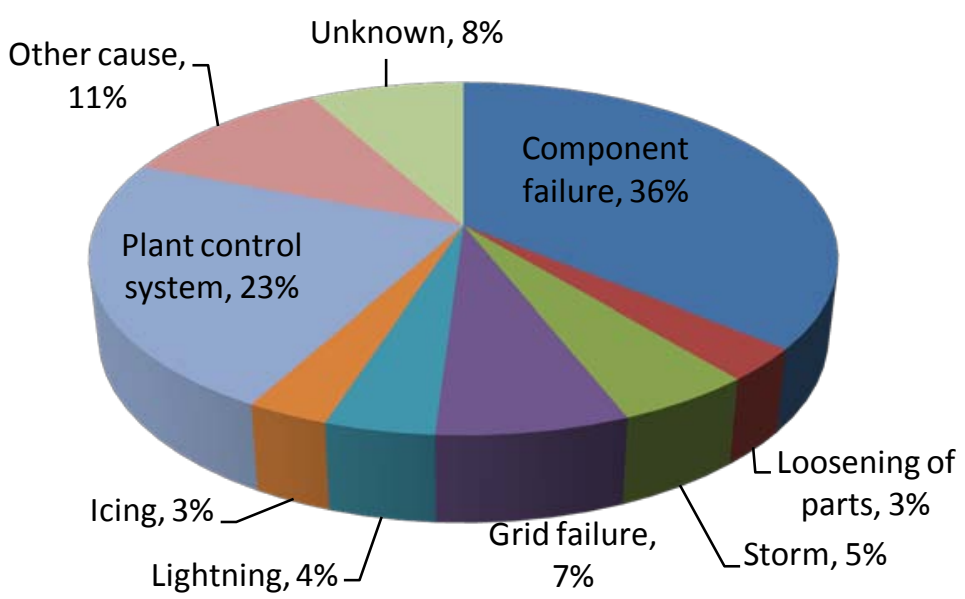

Fig. 1 Statistical analysis for wind turbines failure causes [9]

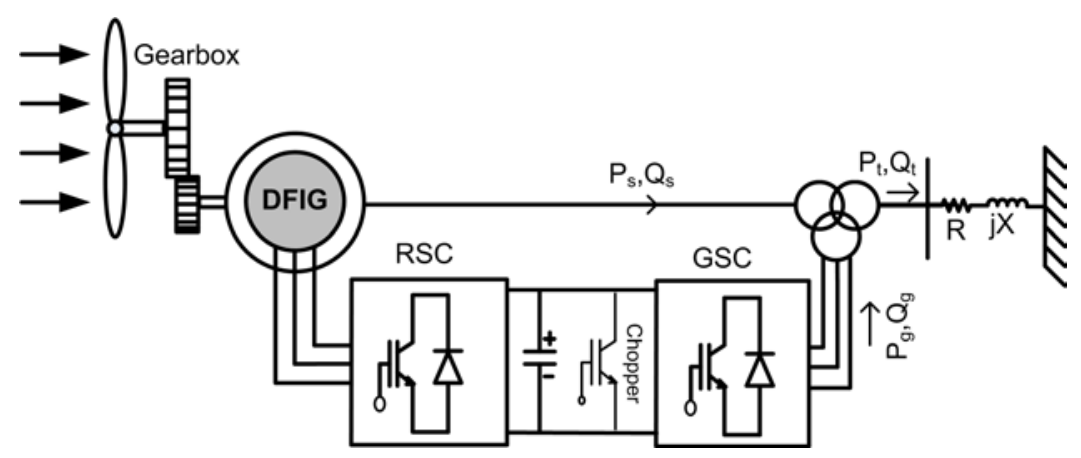

Fig. 2 Typical configuration of DFIG connected to the grid 


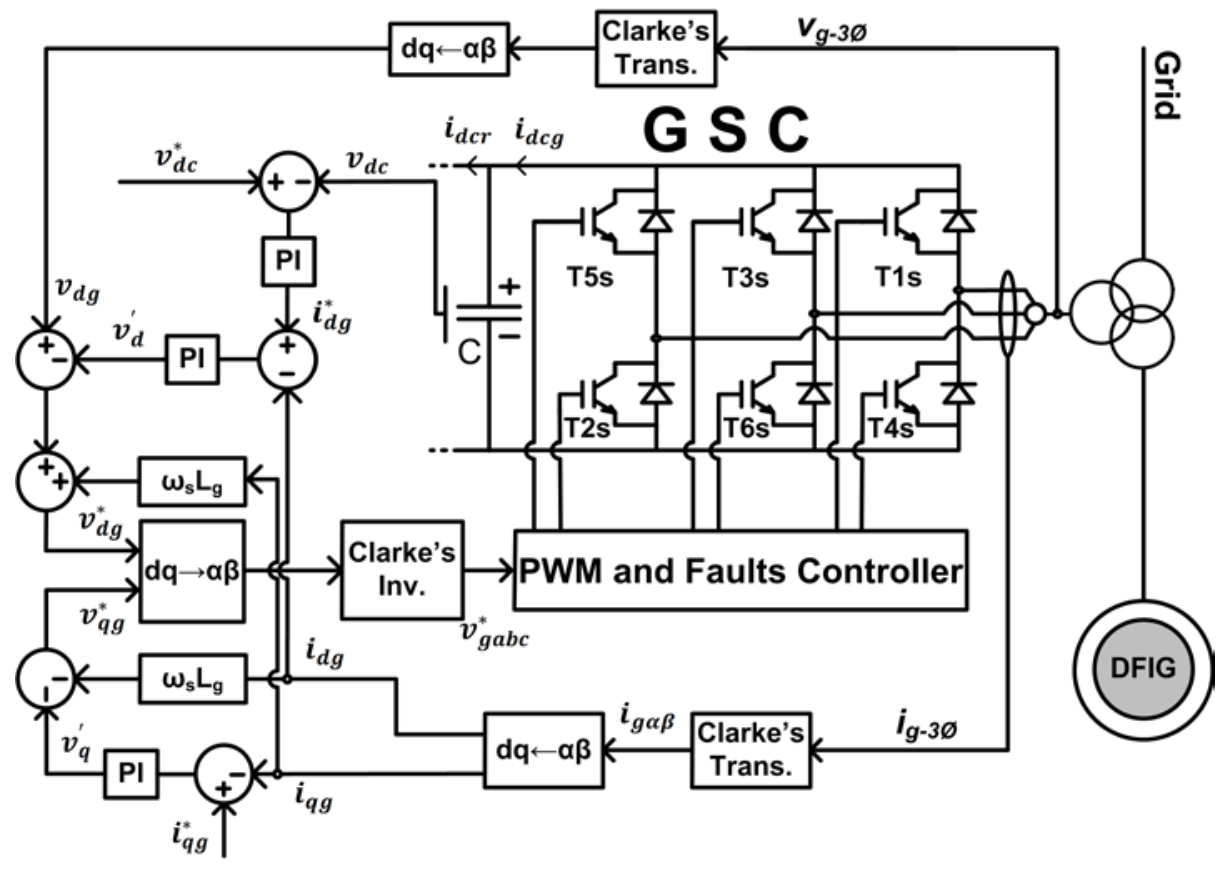

Fig. 3 The grid side vector control system

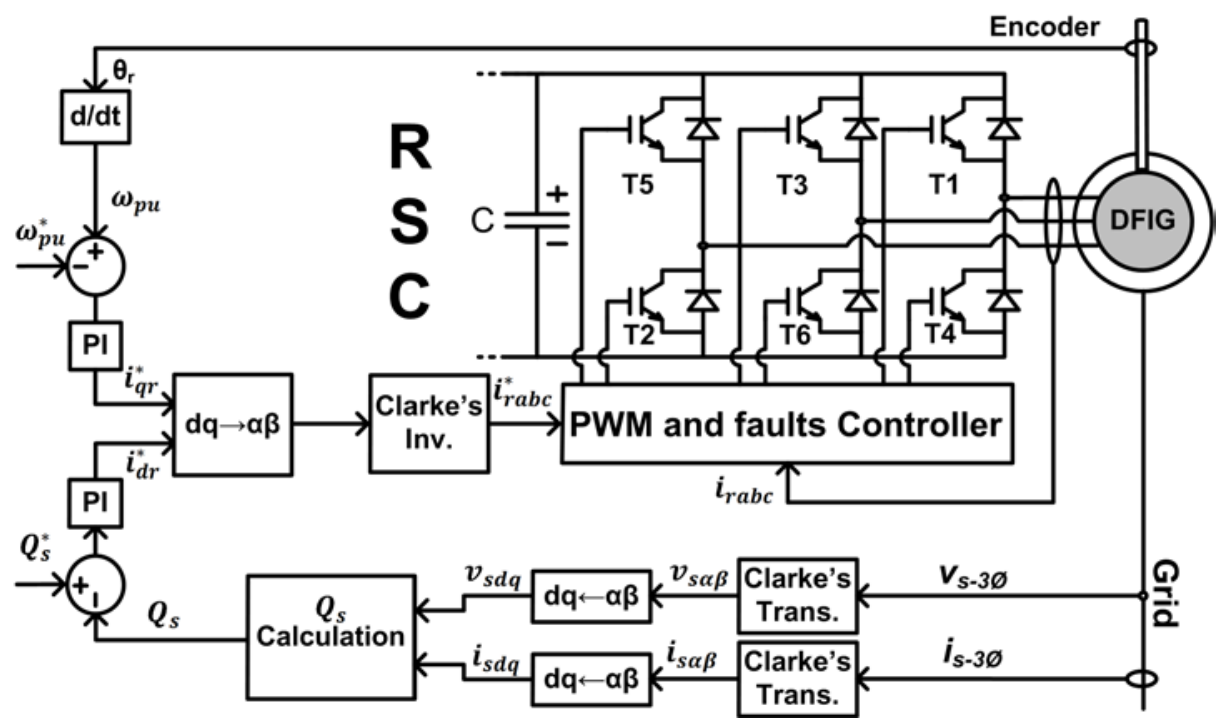

Fig. 4 The rotor side vector control system

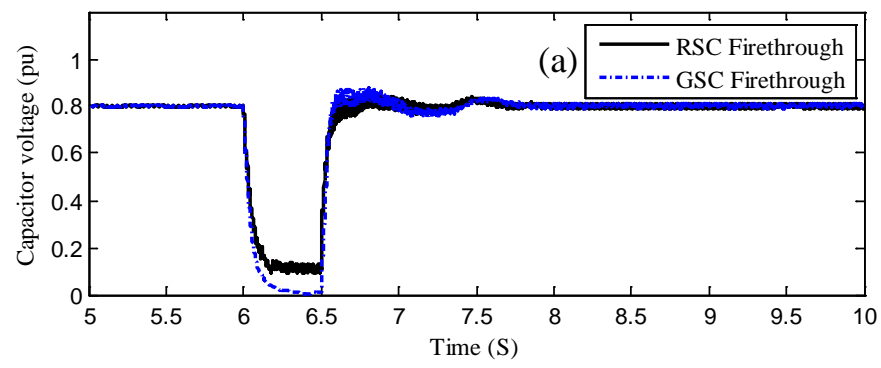



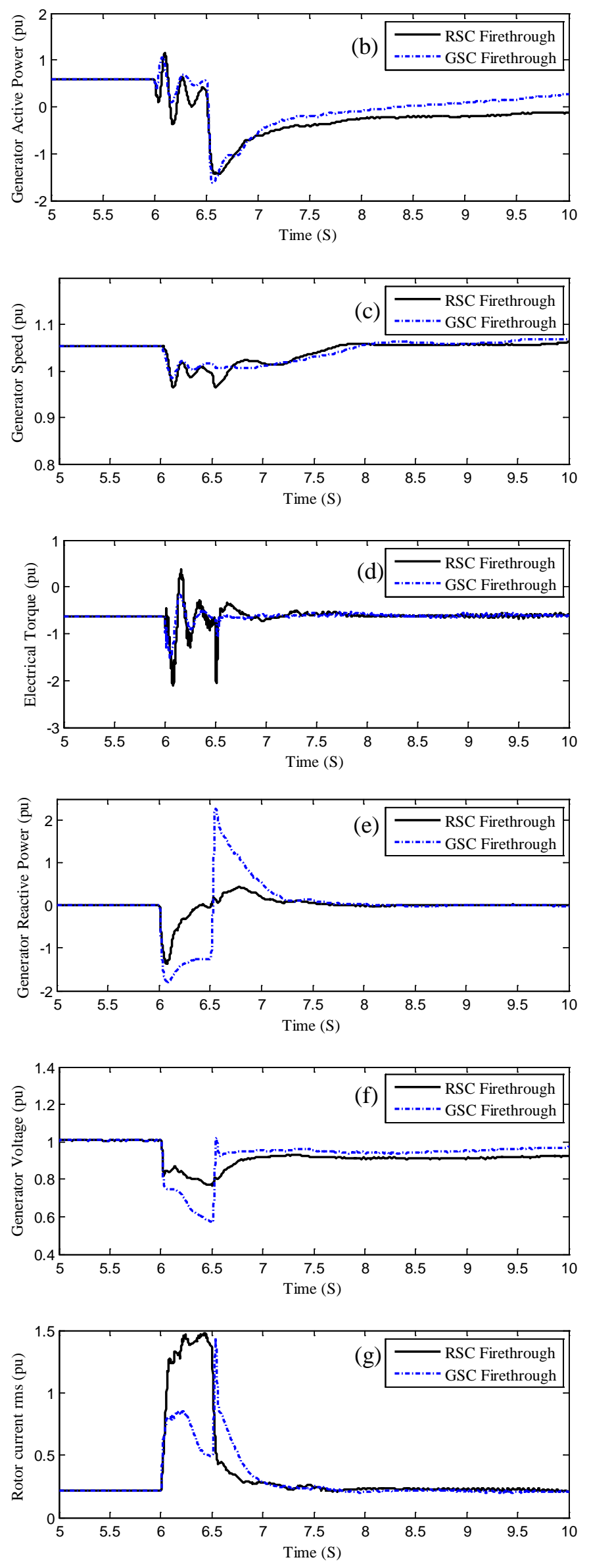

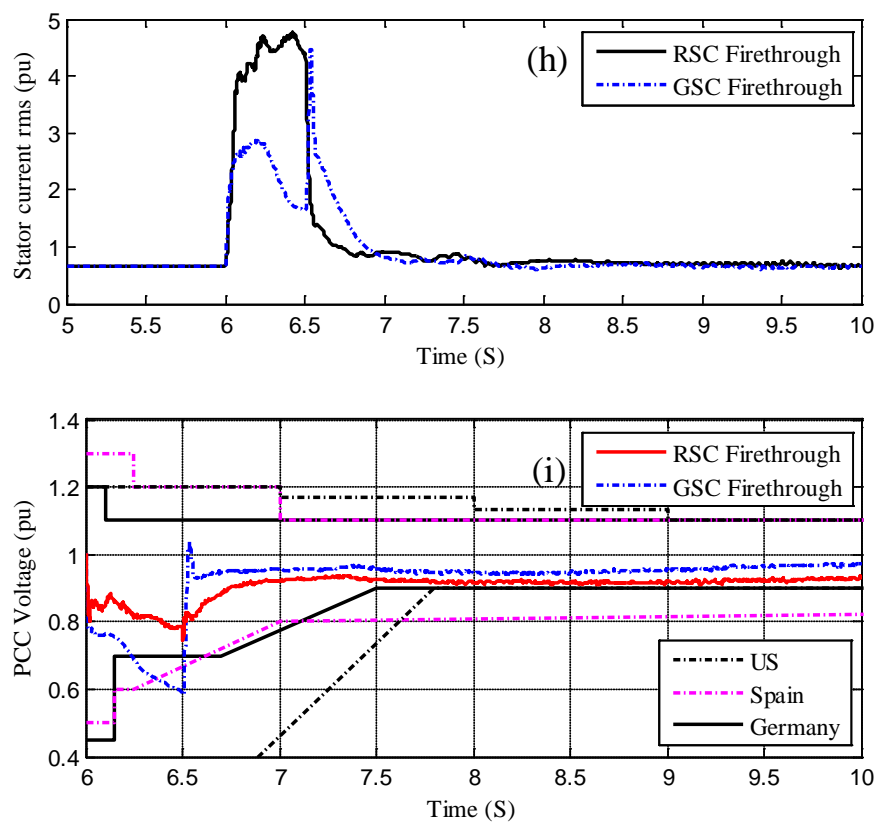

Fig. 5 WECS performance under intermittent fire-through fault within RSC and GSC
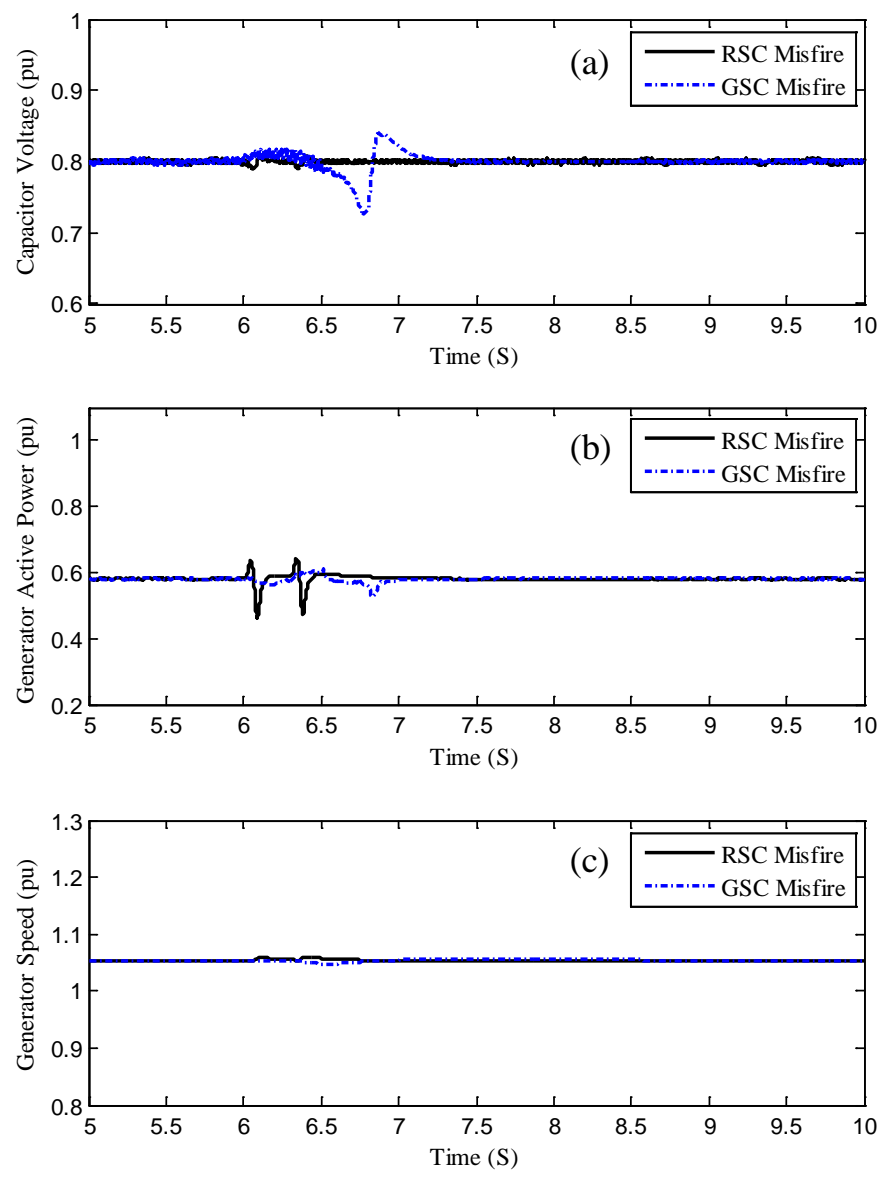

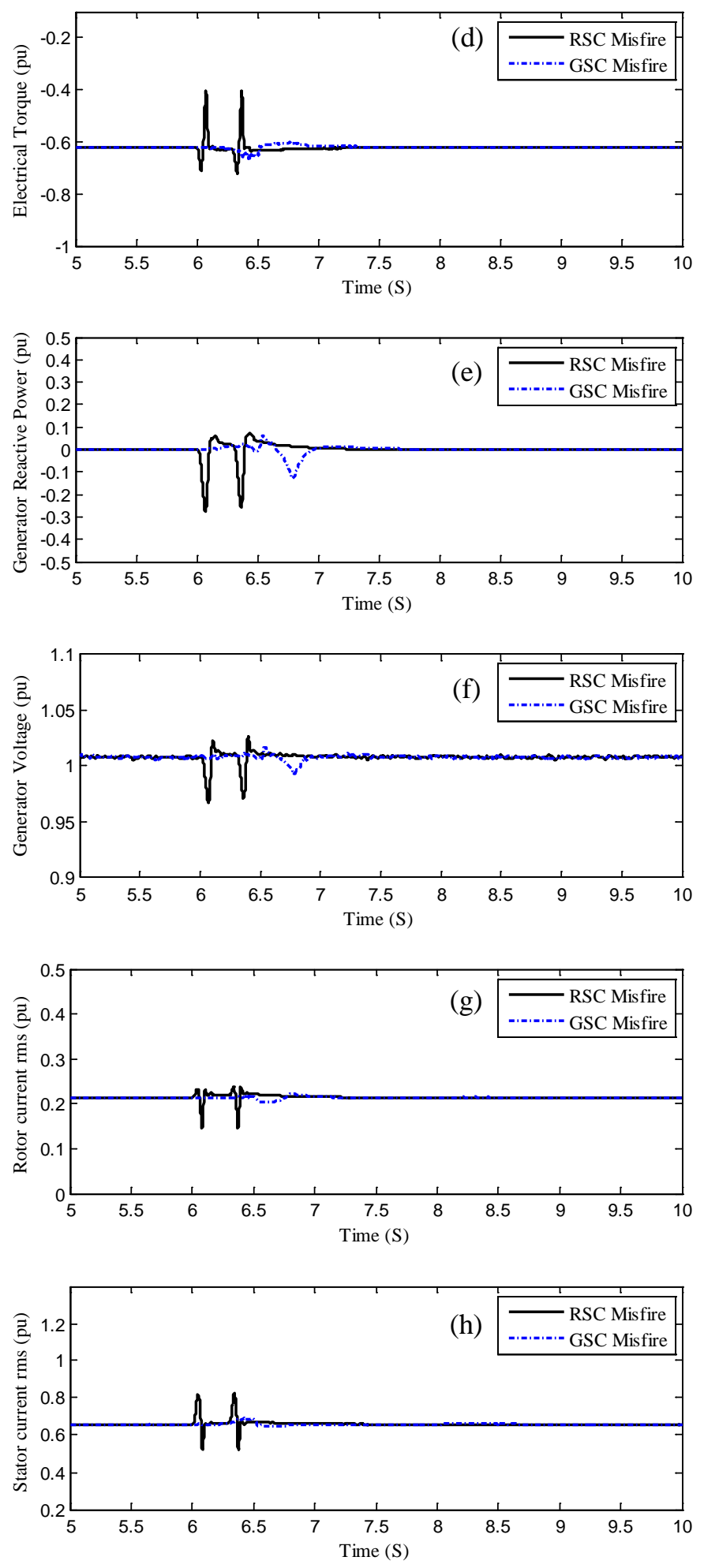


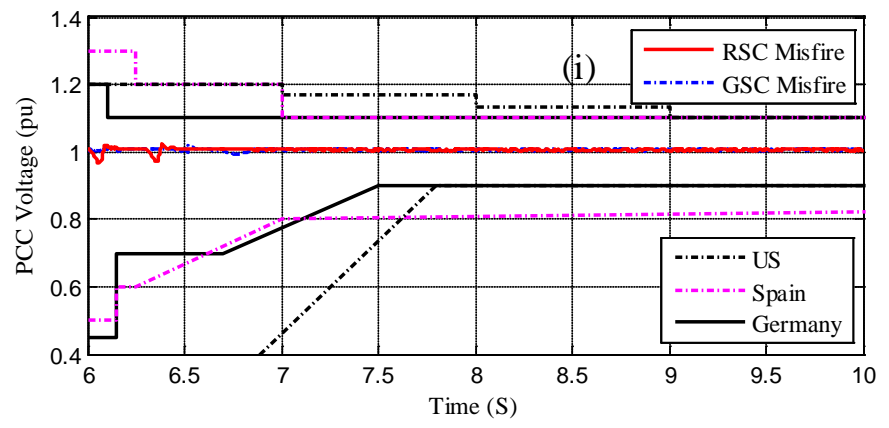

Fig. 6 WECS performance under misfire fault within RSC and GSC
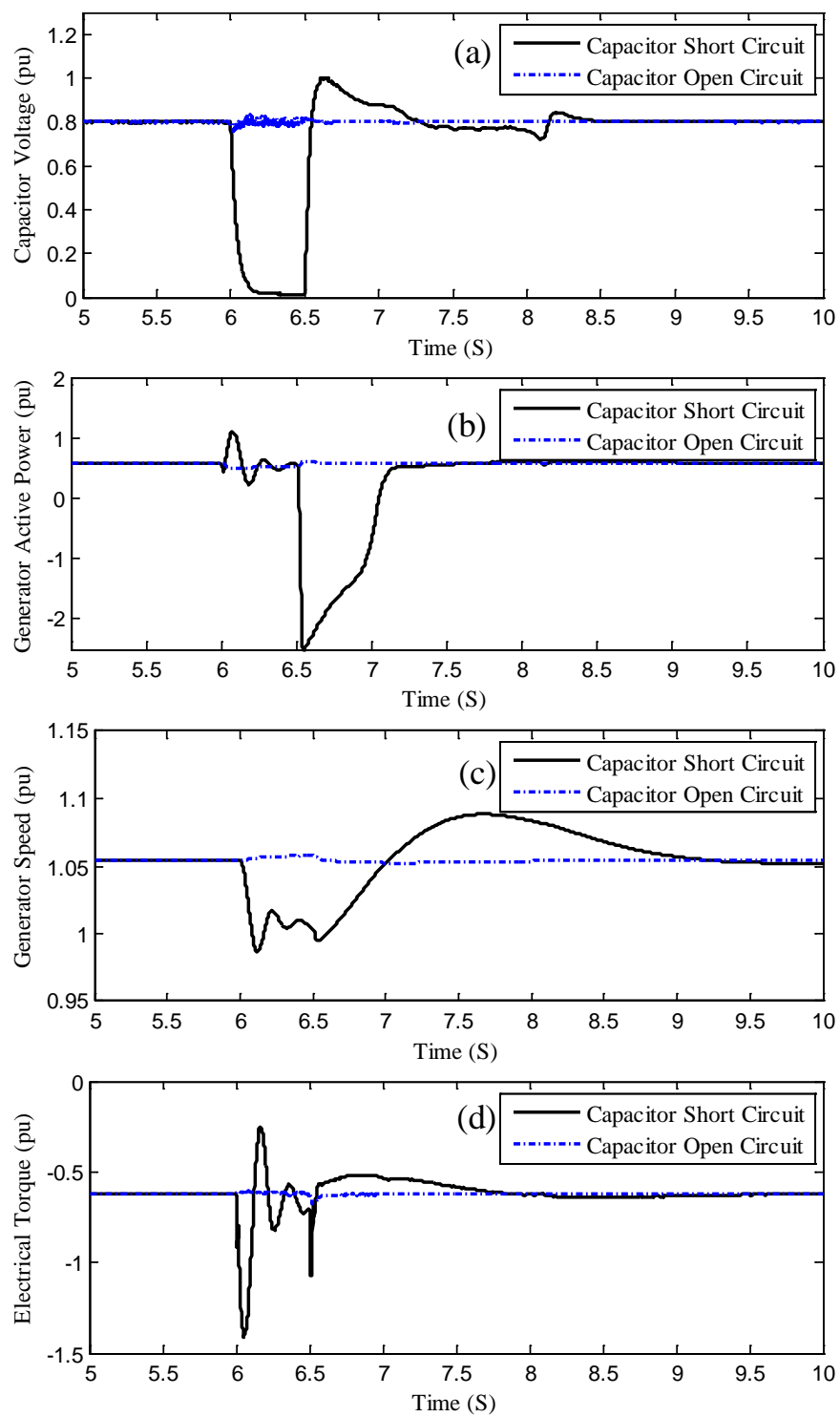

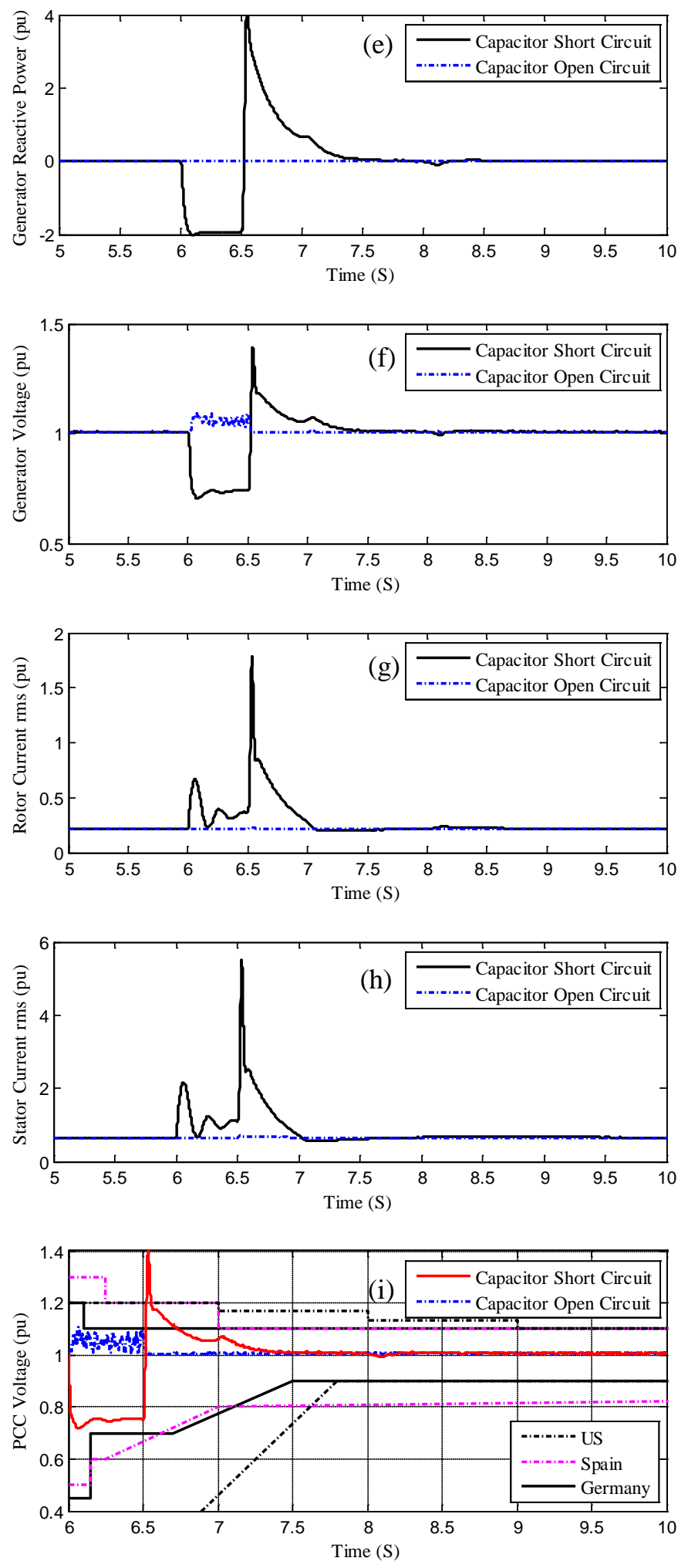

Fig. 7 WECS performance under short and open the capacitor terminals 